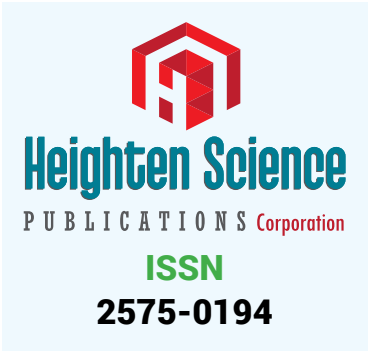

*Address for Correspondence: Yimer Mihretie, Jigjiga University, Somali region, Jigjiga and P. O Box: 1020, Ethiopia, Email: luguy00@gmail.com

Submitted: 01 November 2017

Approved: 08 November 2017

Published: 09 November 2017

Copyright: @ 2017 Mihretie Y. This is an open access article distributed under the Creative Commons Attribution License, which permits unrestricted use, distribution, and reproduction in any medium, provided the original work is properly cited.

Keywords: Complementary feeding; Gode; Infants; Malnutrition; Stunting; Wasting
Research Article

\section{Assessment of Complementary Feeding Practice of infants and young children aged 6-23 months in Gode Town, Somali Regional State of Ethiopia}

\author{
Yimer Mihretie* \\ Jigjiga University, Somali region, Ethiopia
}

\section{Abstract}

Malnutrition is the largest risk factor caused by inadequate nutrition that leads to childhood morbidity and mortality, as well as inadequate growth and development. Infants are at increased risk of malnutrition by six months, when breast milk alone is no longer sufficient to meet their nutritional requirements. However the factors associated with nutritional status of infants after 6 months of age have received little attention in pastoralist communities of Ethiopia. The aim of this study was to assess the complementary foods of infants and young children (6-23 months) in Gode town of Kebele 01. The prevalences of wasting, stunting and underweight among infants and young children were $6.1 \%, 56.1 \%, 10.0 \%$ reespectively. Undernutrition is a public health problem among infants and young children in Gode town of Kebele 01 . Breastfeeding was slightly positive associated with lower chances of wasting at $r=0.61, p=0.01$ and underweight at $r=0.331, p=0.01$. While diarrheal disease was associated with higher chances of wasting and underweight. Initiation of complementary food was slightly positive association with wasting at $r=0.179, p=0.05$.

\section{Introduction}

\section{Background}

Malnutrition is the largest risk factor in the world for disability and premature mortality among young children, especially in developing countries [1]. Although the condition is entirely preventable, malnutrition is a significant underlying factor in more than half of the deaths of young children in these countries [2]. Malnutrition is a background factor for deaths from diarrhea, measles, acute respiratory infection, meningitis and malaria [2]. In Ethiopia, 40\%, 29\% and 10\% of children under five years of age are stunted, wasted and underweight, respectively [3]. An Ethiopian child is 30 times more likely to die by his or her fifth birthday than a child in Western Europe and the most common cause of child death is the interacting combination of malnutrition and infection [4]. In UNICEF's conceptual framework for determinants of nutritional status, maternal and child care practices have been given due attention in addition to sufficient food supply at the household level, access to health services and a clean environment [5]. Some children in low-income countries with high rates of malnutrition grow normally due to better education and household management, or they are coping skills of their mothers [6]. Moreover, proper feeding practices, which ensure intake, are as important as the provision of complementary foods that meet nutritional requirements.

Appropriate child feeding practices and behaviors of parents have a positive effect on growth of infants and young children [7]. For instance, an analysis of data sets 
from several Latin American countries demonstrated that appropriate breastfeeding and complementary feeding practices were positively associated with child heightfor-age in most of the countries studied [6]. Transition from exclusive breastfeeding to family foods typically covers the period from 6 to 23 months of age. It is the time when malnutrition starts in many infants, contributing significantly to the high prevalence of malnutrition in children $<5$ years of age worldwide. During this time, complementary foods should be added to the diet of the child [1]. It is needed to fill the gap in energy and iron and other essential nutrients, between what is provided by exclusive breastfeeding and the total nutritional requirements of the infant. This gap increases with age, demanding an increasing contribution of energy and nutrients especially iron, from foods other than breast milk [8]. Therefore, it should be timely, adequate, and be given in a way that is appropriate for the age of the child, applying responsive feeding [9]. As the child ages, feeding practices must change in response to the child's changing nutritional requirements, motor skills, and maturing digestive and immune systems [8].

\section{Statement of the problem}

Currently in Ethiopia, but also in many developing countries, interventions mainly address the issue of what to feed infants [10]. Although early childhood malnutrition can be attributable to poverty and lack of resources, family and caregiver characteristics, such as education and household management or coping skills of the mother, can determine normal growth and development. Lack of knowledge regarding appropriate foods and feeding practices can contribute to malnutrition to a greater degree than lack of food [11]. It is not only providing the appropriate combination of complementary foods to meet the child's nutritional needs that is important, but also feeding practices such as frequency of feeds and feeding style need to be considered [12]. However, there has not yet been information known about the current complementary feeding practice in a study area. Therefore, this study aimed to assess the complementary feeding practice of infants and young children aged 6-23 months.

\section{Significance of the study}

This study was focused on the assessment of feeding practice of infants and young children in Gode town Kebele 01 of Somali regional state. In fact, the portion of children who started receiving complementary feeding timely or untimely which can be useful information for programs and call for an interventions should be made to protect and improve child's health. So the major significant of study is that, it provided the relevant information concerning complementary feeding practice being practiced in Gode town Kebele 01. This study has a major significance in revealing the current situation on this matter. The result can also be used to state what kind of intervention or nutrition education is needed for the improvement of community life as recommended by this finding in the rural population.

\section{Methodology}

\section{Study site (Area)}

The study was conducted in Gode town Kebele 01, which is located south eastern part in Somali region, Ethiopia. Gode is $700 \mathrm{~km}$ west far from the capital city of Somali region, Jigjiga. Gode lies in between $5^{\circ} .57^{\prime} \mathrm{N}$ latitude and $43^{\circ} .27^{\prime} \mathrm{E}$ longitude" of the country covers areas which have an elevation of $358 \mathrm{~m}$ above sea level the weather of the city is nearly hot and the temperature ranges $28^{\circ} \mathrm{C}$ to $38^{\circ} \mathrm{C}$. The main staple food is cereal based dishes, the dominant crop grown widely in the Gode are maize, sorghum, rice, fruit, and vegetable

\section{Study period}

This study was conducted from April 2017 to June 2017 in the study area of Gode town kabale 01 of shabele zone, Somali regional state. 


\section{Study population}

The study populations were 180 women whose children are aged between 6-23 months old of age living in Gode town kabale 01, and who have been breastfed for the first 6 months of life and history of breastfeeding and complementary feeding practices at the time of the study.

\section{Sampling}

The source of population in this study included all residents of Gode town Kebele 01 who were history of breastfeeding and complementary feeding practices of infants and young children aged 6-23 month. The sample size was calculated by using the single population proportion formula. Sample size calculation was obtained by using $34 \%$ of prevalence rate with a $95 \%$ confidence level and $5 \%$ tolerable error. The sample size was calculated as follows:

The calculated sample size is:

$$
\boldsymbol{n}=\frac{361}{1+\frac{(361-1)}{355}}=180
$$

Where:

$\mathbf{N}_{\mathbf{o}}=$ Total sample size that was included in this study

$\mathbf{Z}=$ the standard normal deviate at 95\% confidence level (1.96);

$\mathbf{P}=$ prevalence rate is 0.34

$\mathbf{Q}$ is 1-p; which is 0.66

$\mathbf{e}=$ marginal error is 0.05

$$
\boldsymbol{n}_{\boldsymbol{o}}=\frac{(1.96)^{2}(0.34)(0.66)}{(0.05)^{2}}=344
$$

Population correction was done to produce a sample size that was proportional to the population therefore the sample size was calculated as follows;

Non -respond rate $5 \%+344=361$

$$
n=\frac{n_{o}}{1+\frac{\left(n_{o}-1\right)}{N}}
$$

Where: $\mathrm{n}=$ desired sample size $\mathrm{N}=$ the estimate of the population size $=200$

$$
\text { Therefore, } \boldsymbol{n}=\frac{361}{1+\frac{(361-1)}{355}}=180
$$

\section{Sampling technique}

In this study multi-stage sampling method were used, By considering Gode town Kebele 01, (Personal information), three cluster were selected from that Kebele by Purposive sampling technique, then the calculated sample size were proportionally allocated according to household population load of each cluster. Random sampling techniques were also used to identify the study households from each cluster. In cases where there is more than one eligible individual in the selected household, a lottery method was used to pick one, and in the event that there is no eligible person in the selected household, the next doors were visited (Figure 1). 


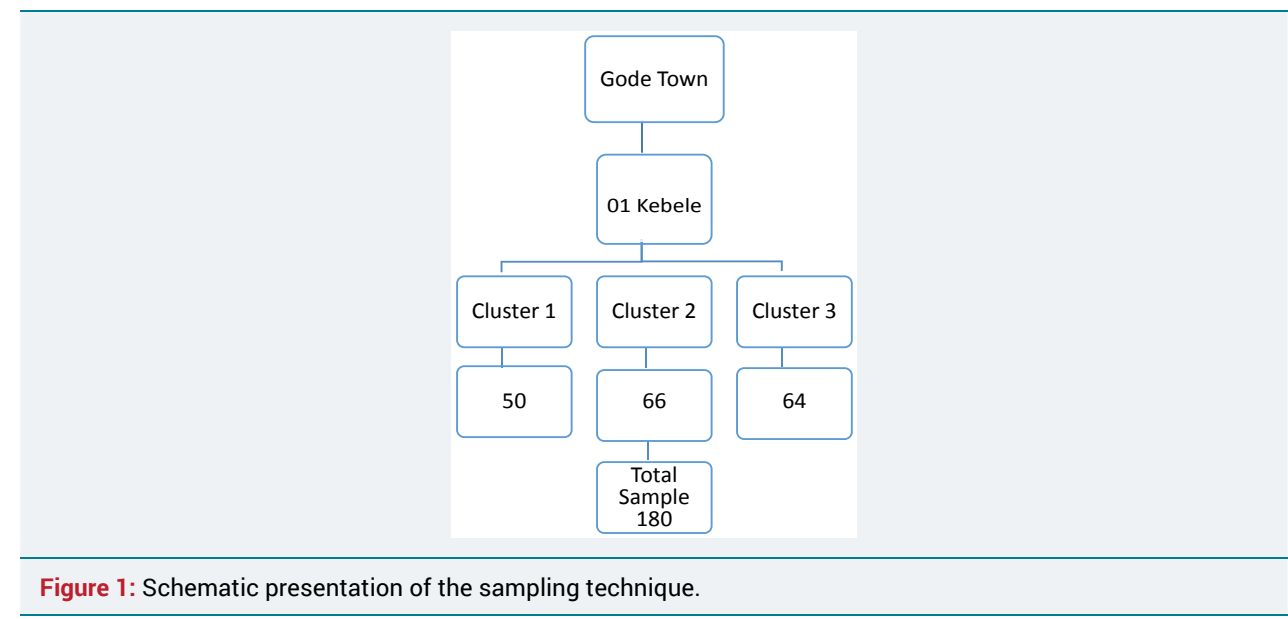

\section{Sample collection procedure}

Data was collected by a face-to-face interview technique using the adapted complementary feeding practices questionnaire. The questionnaire was first prepared in English and later translated into Somali (the local language of the study area.) and back translated into English to check for its conceptual equivalence. Mothers/caregivers was visited the day before to obtain oral consent and asked to maintain regular feeding practices. Other socio-demographic information, such as mothers/caregiver's age and level of education, Household size, parity, and income, were collected by interviewing the mothers/caregivers using the data collection tool.

\section{Data processing and analysis}

All the collected data were checked for completeness and internal consistency by cross checking and then was coded and double entered into computer software package and cleaned for inconsistency. For further analysis, the data was exported to Statistical Package for Social Science (SPSS) version 20 software. The Descriptive statistics was used to express results using frequency, mean and percent (\%).

\section{Data collector}

Data were collected by the researchers who are actually group seven members and brought the reliable data to explore the complementary feeding practices of infants and young children 6-23 months information in the study area.

\section{Eligibility of the subjects}

\section{Inclusion criteria}

1. Infants and young children between 6 and 23 months of age

2. Children who have breastfed.

3. Children who have started eat CF (Complementary Feeding)

\section{Exclusion criteria}

1. Infant and young Children above 2 years and below 6 months.

\section{Ethical consideration}

Ethical clearance was obtained from Jigjiga university department of food science and nutrition. Official letter was sent to Gode town 01 Kebele health office for commencing the study and the data collection was begun after permission and cooperation letter was written to all clusters on which the study was carried out. The study, purpose, procedure and duration, possible risks and benefits of the study were clearly explained for the participants using local language. At household level, informed oral consent was obtained from mothers to precede the data collection process. 


\section{Results and Discussions}

\section{Socio-Economic and demographic characteristics of mothers}

The table 1 indicates the Socio-economic and demographic characteristics of households at Gode town 01 kebele, Somali regional state. In this study, a total of 180 households were participated. The age of respondents range from 20-45years and mean age was $(26.9 \pm 3.8)$ years. More than half of mothers were in the age group of 26-30 years. From the study all the respondents were Muslim religion followers. Regarding with ethnicity all the respondents were belongs to Somali. Concerning the educational status, $60 \%$ of respondents were not taken a formal education, because of lack awareness towards the educational status. This indicates that it is slightly

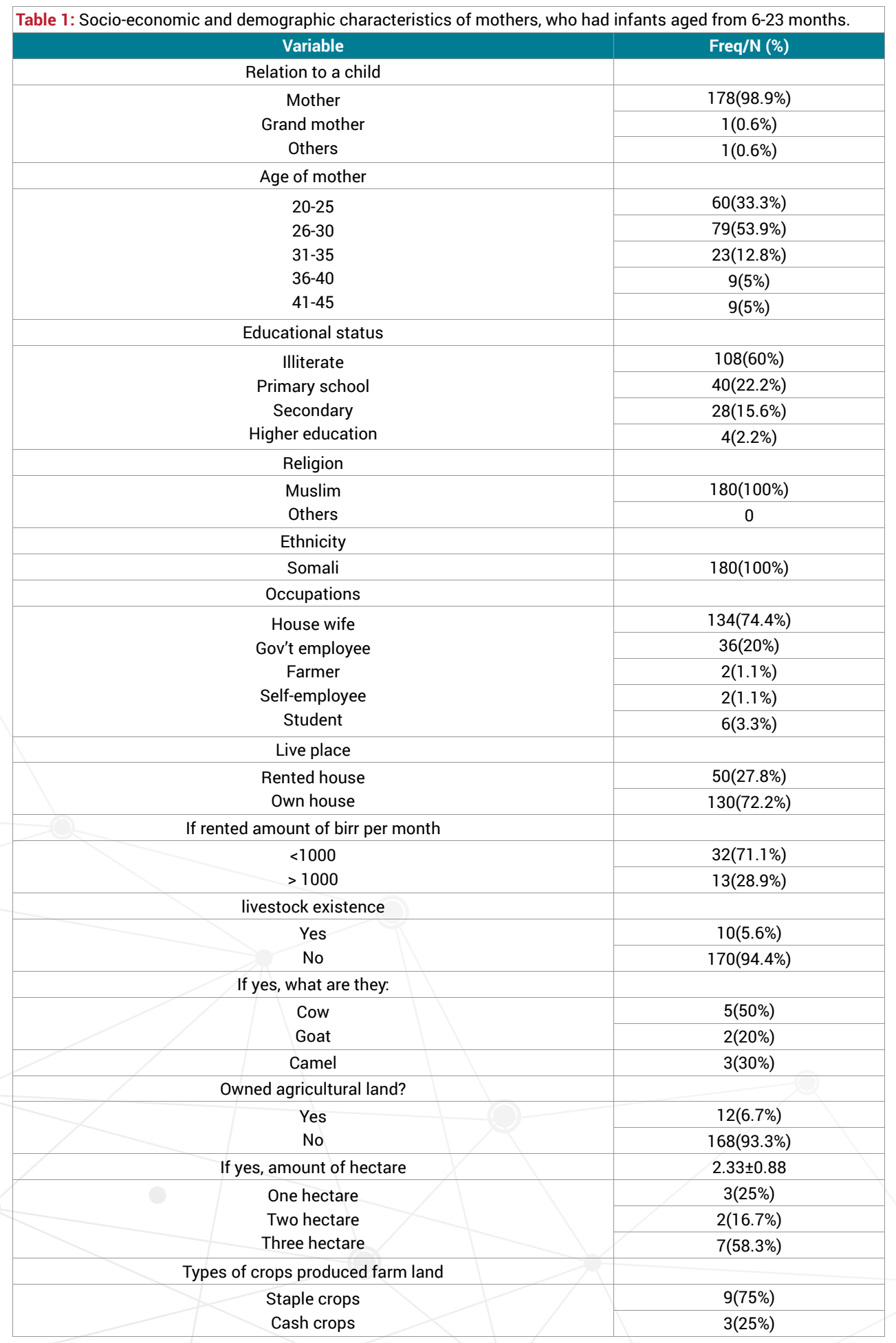


lower than research done in Tigray region report that respondents (72.4\%) were attended formal school [13]. Out of the total households included in this study, more than half respondents were housewife 134(74.4\%). This is in line with the study done in Mekelle University 61.7\% [13]. Also the amount (percent) of farmer and self-employee respondents were equal (1.1\%) by their occupation in our study. Most of the respondents were own houses made of either plastic, some wood or piece of clothes and also almost all of the respondents were no livestock and agricultural land ( above $93.3 \%$ ) that satisfy their needs and respondents that were agricultural land was produce mostly staple crops.

\section{Feeding practice}

Breast feeding and complementary feeding practices: Complementary feeding practices were summarized from the results of the questionnaire survey (Table 2 ). Amongst the mothers studied, more than half of the mothers were currently

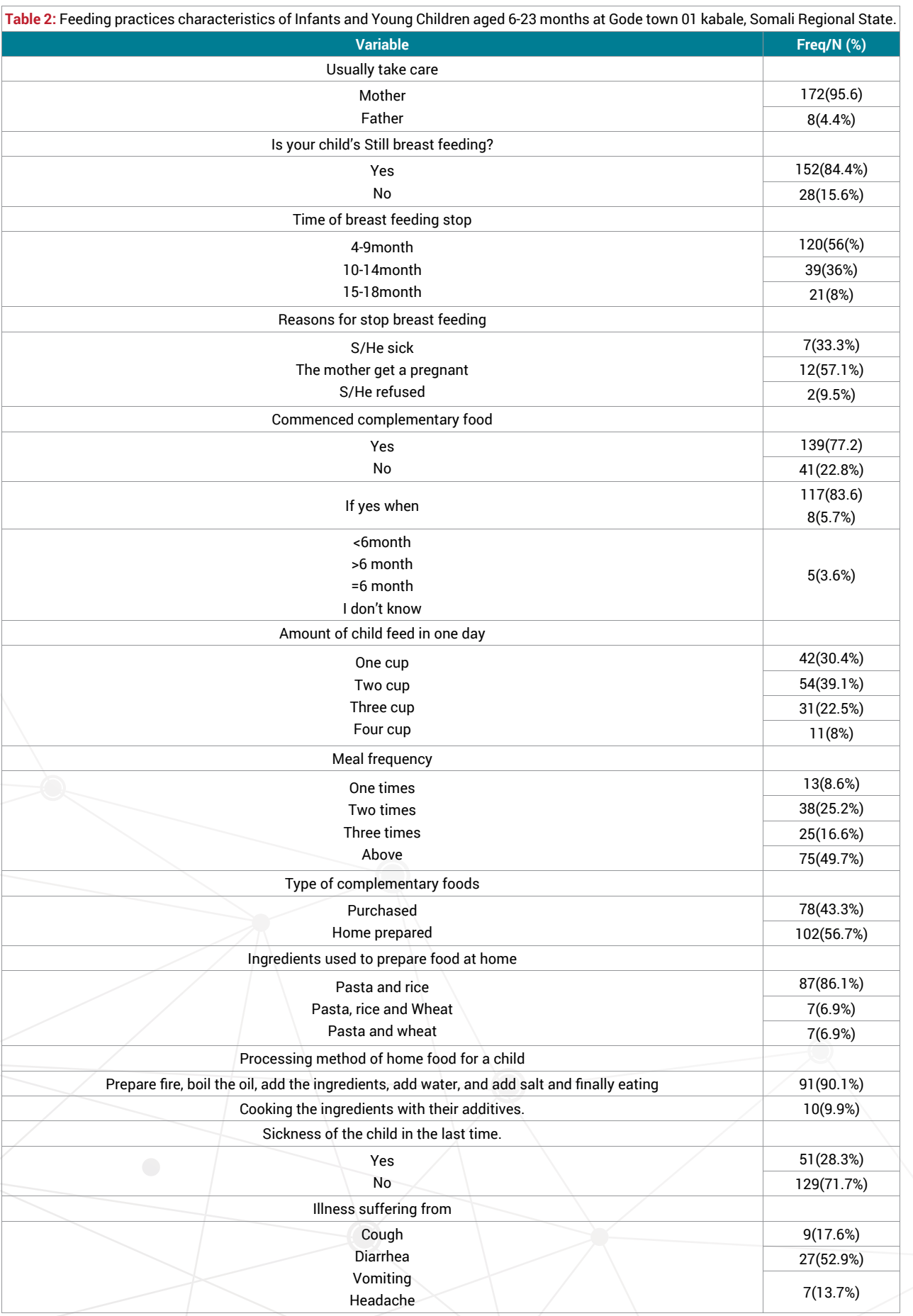


breastfeeding and also more than half of the children were introduced complementary foods after 6 month due to mother's get a pregnant, the child's sickness and also the children were refused the breast milk. Almost all mothers $95.6 \%$ were responsible for care of their infants than other listed care takers. The only foods reported as being prepared specially for the infant, though not necessarily exclusively for infants, were the pasta, rice and wheat $86.1 \%, 6.9 \%, 6.9 \%$ respectively. Most complementary foods given were the same as those prepared for other family members and also they were used mostly foods prepared at home.

Food processing practices: From the questionnaire results, 9.9\% of mothers report ever simply cooking the ingredients with their additives to feed their infants. But most of households use the same method of processing a food. That is first Prepare fire, boil the oil, add the ingredients, add water, and add salt and finally eat 102 (56\%).

Nutritional status of the infants and young children aged 6-23months:The results of Anthropometric were analyzed by using WHO Anthro ENA software categorized as: stunted, wasted and underweight to check the nutritional indicators [14]. It demonstrated that malnutrition is prevalent among infants and young children in Gode town 01 kebele. The prevalence of wasting, stunting, underweight among infants and young children in this study were $6.1 \%, 56.1 \%, 10.0 \%$ respectively.

In the current study the prevalence of wasting was lower than the study reported in the 2011 EDHS prevalence of wasting, because of positive association of maternal education with wasting indicators of nutritional status. Also the stunting prevalence (56.1\%) in current study was higher than that of 2011 [3] EDHS (29\%). This is Because of negative association of income level and mostly low association of breast feeding with stunting indicator of nutritional status. But our underweight indicator is in line with 2011 EDHS study that is $10 \%$.

A study from North Showa, Ethiopia, reported that the prevalence of wasting, stunting, and underweight were $10.6,54.2$, and $40.2 \%$ respectively [15]. In the current study, the prevalence wasting (6.1) was found to be slightly lower due to mother's educational status towards wasting indicator of child's nutritional status. While the prevalence of stunting relatively higher as compared to the study from North Showa, Ethiopia. This is due to the mother's lack of information about food and nutrition education to us e the food in recommended and safety strategies. Also in the present study the associated factors that cause wasting and underweight were more than half percent of diarrheal disease and breastfeeding. Diarrheal disease was associated with higher chances of wasting and underweight while breastfeeding was found to be protective for wasting and underweight. Childhood morbidity status, especially diarrhea, has been reported in other studies to have a negative effect on growth of children, specifically on weight gain [7]. In this study despite of diarrhea, there were other conditions such as cough, vomiting, headache were affect both dietary intake and utilization, consequently affecting a child's nutritional status. These were because of the problem of usually care takers that have a lack of sanitation of good quality of food, environment and proper handling practices related to eating habits. In this study also, breastfeeding was significantly strong associated with lower chances of wasting. There is evidence that breastfeeding was associated with weight gain [16]. Breastfeeding is also associated with lower incidence (occurrence) of child morbidity [17]. This could be due to the immunological, hygienic and nutritional advantages of breastfeeding. These additional advantages of breastfeeding have a role in prevention of malnutrition.

\section{Characteristics of the child's}

The table 3 indicates that the child's characteristics that were aged 6-23 months. In this study, a total of 180 households were participated. The ages of infant were range 
Table 3: Feeding practices characteristics of Infants and Young Children aged 6-23 months at Gode town 01 kabale, Somali Regional State.

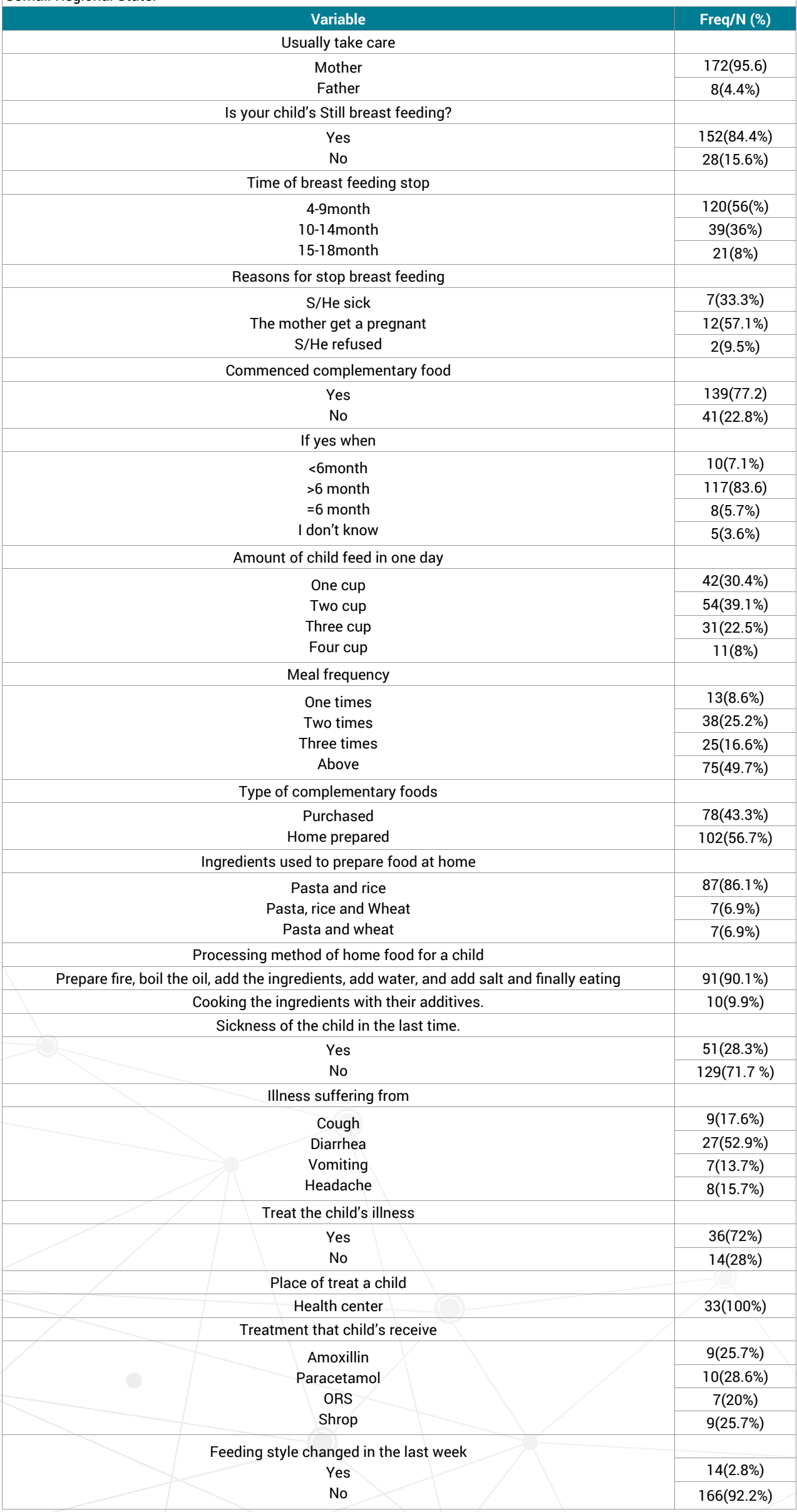




\begin{tabular}{|c|c|}
\hline If yes, How has it changed? & $14(100 \%)$ \\
\hline Disease reduce the appetite & $14(100 \%)$ \\
\hline Reasons for changed feeding style & \\
\hline Because of disease & $129(71.7 \%)$ \\
\hline Introduced solid/semisolid food for infants & $51(28.3 \%)$ \\
\hline Yes & \\
\hline If yes, when? & $121(93.8 \%)$ \\
\hline $4-9$ month & $7(5.4 \%)$ \\
\hline $10-14$ month & $1(0.8 \%)$ \\
\hline
\end{tabular}

from 6-23 months and mean age was 13.6 \pm 2.7 months. Out of the total sample, more than half of the male children (53.9\%) were more participated than female (46.1\%). More than one third of children participated were11-15 months of age (38.9\%) and children aged from 21-23 months were participated in a very small amount by a percent of $13.3 \%$. Regarding with the length and weight more than one third of the children were $66-75 \mathrm{~cm} 69(38.3 \%)$ and more than half of the children were $6-10 \mathrm{~kg}$ 95(52.8\%) respectively.

Factors associated with nutritional status of infants and young children 6-23 months

The tables 4,5 indicates the influence of socio-demographic and feeding practices on the nutritional status of infants and young children 6-23 months. In this study maternal level of educational status were significantly positive associated with WAZ and WHZ nutritional status of the infants $(\mathrm{P}=0.01)$. This implies that education are important factors in mothers' knowledge of complementary feeding. This is consistent with the study done in Nigeria [18]. A study done in Zambia showed that the prevalence of wasting did have a significant association with maternal education in which wasting prevalence was minimal in households with educated mothers [19]. Level of education and occupation of the mothers significantly influenced the complementary feeding practices similar to reports from other researcher [20]. The living place has also negatively associated with WAZ, WHZ. This is due to the lack of clean environment and agricultural land that produce a type of crops (staple and cash crops) that results inadequate nutrition lead to affect the nutritional status of the children (from FDG).

Income level was negatively associated with HAZ nutritional status of the infants, but significantly positive association with $\mathrm{WAZ}$ at $\mathrm{P}=0.05$. Because, income is the major determination of nutritional status and it depends on individuals ability to use the income as a function. In this study, sex of the child is the most important factor that influence positively the nutritional status at $\mathrm{P}=0.01$. In contrast to the other studies [21]. Mothers who have male child were three times more likely to timely initiate complementary feeding than female child. This might be due to traditional gender norm that discriminate female feeding. Age of the child was positive association with a MUAC at $\mathrm{P}=0.01$. This implies that as the ages of the child's were increase the MUAC measurement were also increase slightly. Appropriate breast-feeding is fundamental to children's survival, growth and development [22]. So in this study, breast feeding were positively associated with HAZ indicator of nutritional status at $\mathrm{P}=0.01$ to protect child's health wellbeing. Complementary food were negatively associate with MUAC a positively with WAZ at $\mathrm{P}=0.05$. This were because of poor good hygiene of food, quality of food and inappropriate nutrient and complementary feeding initiation at recommended age ( 6 months) were associated with reduced odds of stunting. A study done in Sidama zone reported that dietary inadequacy and low diet quality in terms of availability of micronutrients had a significant negative association with child growth [23]. Introduced Solid and semi solid foods were positively associated with WAZ at $\mathrm{P}=0.05$. This study revealed that, mothers prepared and initiated solid and semi solid type of complementary food in which the majorities were usually prepared foods like 


\begin{tabular}{|c|c|}
\hline 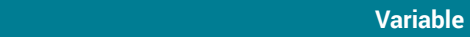 & Freq/N (\%) \\
\hline \multicolumn{2}{|l|}{ Sex } \\
\hline \multirow{2}{*}{$\begin{array}{l}\text { Male } \\
\text { Female }\end{array}$} & $97(53.9 \%)$ \\
\hline & $83(46.1 \%)$ \\
\hline \multicolumn{2}{|c|}{ Age in months } \\
\hline \multirow{4}{*}{$\begin{array}{c}6-10 \\
11-15 \\
16-20 \\
21-23\end{array}$} & $47(26.1 \%)$ \\
\hline & $70(38.9 \%)$ \\
\hline & $39(21.7 \%)$ \\
\hline & $24(13.3 \%)$ \\
\hline \multicolumn{2}{|c|}{ Birth order } \\
\hline \multirow{4}{*}{$\begin{array}{l}\text { First } \\
\text { Second } \\
\text { Third } \\
\text { Fourth }\end{array}$} & $78(43.3 \%)$ \\
\hline & $48(26.7 \%)$ \\
\hline & $44(24.4 \%)$ \\
\hline & $10(5.6 \%)$ \\
\hline \multicolumn{2}{|c|}{ Child's brother and sister } \\
\hline \multicolumn{2}{|c|}{ If Yes how many? } \\
\hline \multirow{3}{*}{$\begin{array}{r}1-3 \\
3-7 \\
7-9\end{array}$} & $55(64 \%)$ \\
\hline & $20(23.3 \%)$ \\
\hline & $11(12.8 \%)$ \\
\hline \multicolumn{2}{|l|}{ MUAC } \\
\hline \multirow{4}{*}{$\begin{array}{c}<11 \mathrm{~cm} \\
11-12.5 \\
12.5-13.5 \\
>13.5\end{array}$} & $8(4.4 \%)$ \\
\hline & $53(29.4 \%)$ \\
\hline & $69(38.3 \%)$ \\
\hline & $50(27.8 \%)$ \\
\hline \multicolumn{2}{|c|}{ Weight in kg } \\
\hline \multirow{2}{*}{$\begin{array}{c}6-10 \\
10-15\end{array}$} & $95(52.8 \%)$ \\
\hline & $85(47.2 \%)$ \\
\hline \multicolumn{2}{|c|}{ Length in $\mathrm{cm}$} \\
\hline \multirow{5}{*}{$\begin{array}{l}46-55 \\
56-65 \\
66-75 \\
76-85 \\
86-90\end{array}$} & $4(2.2 \%)$ \\
\hline & $63(35 \%)$ \\
\hline & $69(38.3 \%)$ \\
\hline & $35(19.4 \%)$ \\
\hline & $9(5 \%)$ \\
\hline
\end{tabular}

Table 5: Factors associated with nutritional status among infants and young children in Gode town 01 kebele, Somali Region.

\begin{tabular}{|c|c|c|c|c|c|}
\hline Variable & \multicolumn{4}{|c|}{ R-Value } & \multirow[t]{2}{*}{ P-value } \\
\hline Socio demographic characteristics & MUAC & WHZ & WAZ & HAZ & \\
\hline Maternal education status & - & 0.297 & 0.236 & -- & 0.01 \\
\hline Age of the mother & & & & 0.157 & 0.05 \\
\hline Occupations & & 0.172 & 0.193 & & 0.01 \\
\hline Care giver & & 0.177 & & & 0.05 \\
\hline Living place & & -0.28 & -0.2 & & 0.01 \\
\hline Income level & -2.94 & & 0.363 & -0.296 & 0.05 \\
\hline Agricultural land & & & -0.181 & -0.176 & 0.05 \\
\hline Length & -0.235 & & 0.502 & -0.378 & 0.01 \\
\hline Weight & 0.339 & 0.564 & 0.152 & 0.356 & 0.01 \\
\hline \multicolumn{6}{|l|}{ Feeding practices } \\
\hline Sex of the child's & & 0.241 & 0.16 & 0.147 & 0.01 \\
\hline Age of child's in months & 0.193 & & & & 0.01 \\
\hline Breast feeding & 0.213 & & 0.61 & 0.331 & 0.01 \\
\hline Commenced complementary foods & -0.185 & & 0.179 & & 0.05 \\
\hline Introduced Solid and semi solid foods & & & 0.164 & & 0.05 \\
\hline
\end{tabular}

porridge and soup with cow milk, but they did not accept cow milk as complementary food and they introduce mostly at 4-9 months. The study done in United Arab Emirate showed that, $30 \%$ of the infants were given non milk fluids; the majority of the infants (83.5\%) received solid food before the age of 6 months [24].

\section{Conclusion}

The prevalence of under nutrition (including wasting, stunting and underweight) is a public health problem, among infants and young children in Gode town area, Somali 
region, Ethiopia. Not breastfeeding during the previous day and diarrheal disease were found to be independent or freely predictors of increased or chances for wasting and underweight. Inappropriate ages of complementary feeding initiation were identified to be significant predictors of stunting. Interventions to improve breastfeeding practices, and timely initiation of complementary feeding are the most important to reduce under nutrition in Gode town 01 kabale, Somali region. Besides those nutrition interventions, prevention of diarrheal disease and would have important effects in reduction of under nutrition.

\section{References}

1. Müller O, Krawinkel M. Malnutrition and health in developing countries. CMAJ. 2005; 173: 279-86. Ref.: https://goo.gl/SrR5Eb

2. Pelletier DL. The relationship between child anthropometry and mortality in developing countries: implications for policy, programs and future research. J nutroct. 1994; 124: 2047S-2081S.

3. Ethiopian demographic health survey. Complementary feeding practice for infants6-23 months at filtu woreda, Somali regional state. 2011.

4. Joan J, Mesfin BH. Report on review of Incorporation of Essential Nutrition Actions into Public Health Programs in Ethiopia. Food and Nutrition Technical Assistance (FANTA) Project. 2008. Ref.: https://goo.gl/LQ9JdK

5. UNICEF. The Care Initiative Assessment, Analysis, and Action to Improve Care for Nutrition. UNICEF Nutrition Section. 1997.

6. Pelto GH. Improving Complementary Feeding Practices Responsive Parenting As a Primary Component Of Intervention To Prevent Malnutrition In Infancy and Early Childhood. Pediatrics. 2000; 106: 1300-1301. Ref.: https://goo.gl/rH6JHw

7. Saha KK, Persson L, Rasmussen KM, Arifeen SE, Frongillo EA, et al. Appropriate infant feeding practices result in better growth of infants and young children in rural Bangladesh. Am J ClinNutr. 2008; 87: 1852-1859. Ref.: https://goo.gl/BhETH9

8. World Health Organization. Infant And Young Child Feeding: Model Chapter For Textbooks For Medical Students And Allied Health Professionals. Geneva: WHO Press. 2009.

9. World Health Organization. Essential Nutrition Actions: Improving Maternal, Newborn, Infant And Young Child Health And Nutrition. Geneva: WHO Press. 2013.

10. Engel PL, Bentley M, Pelto G. The role of care in nutrition programs: current research and a research agenda. Proceedings of the Nutrition Society. 2007; 59: 25-35. Ref.: https://goo.gl/ch68ZH

11. Penny ME, Creed-Kanshiro HM, Rbert RC, Narro MR, Caulfield LE, et al. Effectiveness of An Educational Intervention Delivered Through The Health Services To Improve Nutrition In Young Children: A Cluster-Randomized Controlled Trial. Lancet. 2005; 365: 1863-1872. Ref.: https://goo.gl/QkyjxK

12. Patric $\mathrm{H}$, Nicklas TA, Hughes SO, Morales $M$. The benefits of authoritative feeding style: caregiver feeding styles and children's food consumption patterns. Appetite. 2005; 44: 243-249. Ref.: https://goo.gl/4NjQBG

13. Fisaha Haile. Magnitude and Factors Associated with Appropriate Complementary Feeding among Mothers Having Children 6-23 Months-of-Age in Northern Ethiopia; A Community-Based CrossSectional Study. 2014; 2: 36-42. Ref.: https://goo.gl/BqKDKj

14. WHO. WHO Multicenter Growth Reference Study Group. WHO Child Growth Standards: Length/ Height-for-Age, Weight for-Age, Weight-for-Length, Weight-for-Height and Body Mass Index-for-Age: Methods and Development, World Health Organization, Geneva. 2006.

15. Aweke KA, Habtamu F, Akalu G. Nutritional Status of Children in Foodlnsecure Households in Two Districts of North Showa Zone, Ethiopia. Afr JFood AgricNutr Dev. 2012; 12: 5915-5927. Ref.: https://goo.gl/sddBz6

16. Disha AD, Rawat R, Subandoro A, Menon P. Infant and young child feeding(IYCF) practices in Ethiopia and Zambia and their association with childnutrition: Analysis of demographic and health survey data. Afr J Food AgricNutr Dev. 2012; 12: 5895-5914. Ref.: https://goo.gl/16n1bk

17. Koyanagi A, Humphrey JH, Moulton L, Ntozini R, Mutasa K, et al. Effect ofearly exclusive breastfeeding on morbidity among infants born to HIV-negativemothers in Zimbabwe. Am J ClinNutr. 2009; 89: 1375-1382. Ref.: https://goo.gl/YWNsw8 
18. Foluke, Sundlay, Aderibigde, Oluwanfun. Complementary feeding, knowledge practice,and dietery diversity among months of under five children in an urban community in lagos, Nigeria. Int $\mathrm{j} \mathrm{MCH}$ and AIDS. 2017; 6: 46-59.

19. Masiye F, Chama C, Chita B, Jonsson D. Determinants of child nutritionalstatus in Zambia: An analysis of a national survey. Zambia SocSci J. 2010; 1: 29-42. Ref.: https://goo.gl/a5XGzH

20. World Health Organization. Complementary feeding. 2016.

21. Ashmika M, Deerajen R, Pugo-Gunsam P, Rajesh J. An Assessment of the Breastfeeding Practices and infant feeding pattern among mothers in Mauritius. J Nutri Metabolism. 2013. Ref.: https://goo.gl/Z4BenF

22. Beyene TT. Predictors of nutritional status of children visiting health facilities in Jimma Zone, South West Ethiopia. Int J AdvNursSciPract. 2012; 1: 1-13. Ref.: https://goo.gl/dvucLd

23. Gibson RS, Abebe Y, Hambidge KM, Arbide I, Teshome A, et al. Inadequate feeding practices and impaired growth among children fromsubsistence farming households in Sidama, Southern Ethiopia. MaternChildNutr. 2009; 5: 260-275. Ref.: https://goo.gl/y5xHhV

24. Radwan. Patterns and determinants of breastfeeding and complementary feeding practices of Mothers in the United Arab Emirates. BMC Public Health. 2013; 13: 171. Ref.: https://goo.gl/vcdw91

25. Ma'alin A, Birhanu D, Melaku S, Tolossa D, Yuusuf Mdet al. Magnitude And Factors Associated with Malnutrition among Children 6-59 Months of Age in Shinile Woreda, Reginal State. BMC Nutrition. 2016; 2: 44. Ref.: https://goo.gl/PVYKN3

26. Mesfin A, Henry C, Girma M, Susan JW. Use of Pulse Crops in Complementary Feeding of 6-23-MonthOld Infants and Young Children in Taba Kebele, Damot Gale District, Southern Ethiopia. J Public Health Africa. 2015; 6: 357. Ref.: https://goo.gl/zoCBJi

27. Baye K, Guyot JP, Icard-Vernière C, Mouquet-Rivier C. Nutrient intakes from complementary foods consumed by young children (aged 12-23 months) from North Wollo, northern Ethiopia: the need for agro-ecologically adapted interventions. Public health nutrition. 2013; 16: 1741-1750. Ref.: https://goo.gl/nMpsWA

28. Dewey KG, Brown KH. Update on technical issues concerning complementary feeding of young children in developing countries and implication for intervention programs. Food and Nutrition bulletin. 2003; 24: 5-28. Ref.: https://goo.gl/MgMdvo

29. Dewey KG. Nutrition, growth and complementary feeding of the breastfed infants. Pediatrics. American clinical nutrition. 2001; 48: 87-104. Ref.: https://goo.gl/uWW8oh

30. European Food Safety Authority. Scientific opinion on the appropriate age for introduction of complementary feeding of infants: EFSA. EFSA J. 2009; 7: 1423. Ref.: https://goo.gl/P13nQf

31. Gluck man, Pinal. Factors affect Under nutrition of the mother at conception and during pregnancy. BMC nutrition. 2013.

32. Imdad A, Yakoob MY, Bahutta ZA. Impact of maternal education about complementary feeding and provision of complementary food on child growth in developing countries. BMC Public Health. 2011; 11: S3-S25. Ref.: https://goo.gl/kuwb3V

33. Kakute P, Ngum J, Mitchell P, Kroll K, Forgwei G, et al. Cultural Barriers to Exclusive Breastfeeding by Mothers in a Rural Area of Cameroon, Africa. American College of Nurse-Midwives. 2005; 50: 324328. Ref.: https://goo.gl/DZY6x4

34. Lander R, Enkhjargal TS, Batiargal J, Bolormaa N, Enkhmyagmar D,et al. Poor Dietary Quality Of Complementary Foods Is Associated With Multiple Micronutrient Deficiencies During Early Childhood In Mongolia. J Public Health Nutrition. 2010; 13: 1304-1313. Ref.: https://goo.gl/CjqaZ9

35. Mwaura W, Moloney G. Somali knowledge, attitude and practice study on infant and young child feeding and health seeking practices. United Nations Food and Agricultural Organization/Food Security Analysis. 2007; 36-61.

36. Nestel P, Brined A, Benoist B, Decker E, Ferguson E, et al. Complementary food supplements to achieve micronutrient adequacy for infant and young children. J pediatrics Gastroenterol nutri. 2003; 36: 316-328. Ref.: https://goo.gl/LFd6Q5

37. Ruel MT, Menon P. Factors Causing Malnutrition among under Five Children in Bangladesh. Pakistan J Nutrition. 2006; 5: 558-562. Ref.: https://goo.gl/K9ngPk

38. Shrimpton R, Victora CG, De Onis M, Lima RC, Blossner M, et al. World Timing Of Growth Faltering: Implications For Nutritional Intervention. J Pediatrics. 2001; 107: E75. Ref.: https://goo.gl/eP8Kgh 
39. Stewart CP, Lannott L, Dewey KG, Michaelsen KF, Onyango AW. Contextualizing Complementary Feeding In A Broader Framework For Stunting Prevention. Maternal and Child Nutrition. 2013; 9: $27-$ 45. Ref.: https://goo.gl/z4923n

40. UNICEF. Infant and Young Child Feeding, Nutrition Section Program, UNICEF Pub Med. 2012.

41. UNICEF. United Nation Children's Fund. Improving Child Nutrition, the Achievable Imperative for Global Progress. UNICEF Pub Med. 2013.

42. World Health Organization Geneva. Iron Deficiency Anemia. In Assessment, Editor. Prevention and Control. A Guide for Program Managers. 2001.

43. World Health Organization. Complementary Feeding. Report Of The Global Consultation, And Summary Of Guiding Principles For Complementary Feeding Of The Breastfed Child. Geneva: WHO Press: WHO. 2002

44. World Health Organization. The World Health Organizations Infant-Feeding Recommendation. Bulletin WHO. 1995; 73: 165-174. 